\title{
A Comprehensive Diagnostic Framework for Evaluating Business Intelligence and Analytics Effectiveness
}

\author{
Neil Foshay \\ Schwartz School of Business \\ St Francis Xavier University \\ nfoshay@stfx.ca
}

\author{
William Yeoh \\ Department of Information Systems and Business Analytics \\ Deakin University \\ william.yeoh@deakin.edu.au \\ Yee-Ling Boo \\ School of Business IT and Logistics \\ RMIT University \\ yeeling.boo@rmit.edu.au \\ Kok-Leong Ong \\ La Trobe Business School \\ La Trobe University \\ kok-leong.ong@latrobe.edu.au \\ David Mattie \\ Technology Support Group \\ St Francis Xavier University \\ dmattie@stfx.ca
}

\section{Abstract}

Business intelligence and analytics (BIA) initiatives are costly, complex and experience high failure rates. Organizations require effective approaches to evaluate their BIA capabilities in order to develop strategies for their evolution. In this paper, we employ a design science paradigm to develop a comprehensive BIA effectiveness diagnostic (BIAED) framework that can be easily operationalized. We propose that a useful BIAED framework must assess the correct factors, should be deployed in the proper process context and acquire the appropriate input from different constituencies within an organization. Drawing on the BIAED framework, we further develop an online diagnostic toolkit that includes a comprehensive survey instrument. We subsequently deploy the diagnostic mechanism within three large organizations in North America (involving over 1500 participants) and use the results to inform BIA strategy formulation. Feedback from participating organizations indicates that the BIA diagnostic toolkit provides insights that are essential inputs to strategy development. This work addresses a significant research gap in the area of BIA effectiveness assessment.

Keywords: Business intelligence and analytics (BIA); Diagnostic framework; BIA strategy formulation

\section{Introduction}

Business intelligence and analytics (BIA) can be defined as "the techniques, technologies, systems, practices, methodologies, and applications that analyze critical business data to help an enterprise better understand its business and market and make timely business decisions" (Chen et al., 2012). A recent Gartner worldwide survey of IT spending revealed that BIA technology is consistently in the top three priorities of chief information officers (Gartner, 2014). Moreover, global BIA-related software spending exceeds US\$14 Billion (Gartner, 2014).

While effective BIA capabilities are essential to the success of modern organizations, their deployment is complex, expensive, time consuming and laden with risk (Isik et al., 2011; 
Wixom and Watson, 2010). Expenditures on these systems include technical infrastructure, packaged software licenses, personnel and training. Typically, full implementation costs are measured in millions of dollars (Yeoh and Popovic, 2015). A number of BIA-related maturity models exist today. However, they typically provide insufficient depth to for evaluating an organization's BIA effectiveness on an on-going basis. This is a significant gap in the existing research as BIA capability deployment is an on-going process - you are never 'done' delivering BIA capabilities as they co-evolve with organizational strategy. A key question that must be addressed as BIA capabilities evolve is: how effective are current capabilities and most importantly - what areas need improvement? This question is exceptionally difficult to answer without a robust monitoring and evaluation mechanism. As the management saying goes: "If you can't measure it, you can't manage it." Therefore, the aim of this paper is to apply a design science paradigm to develop a useful and practical BIA effectiveness diagnostics (BIAED) framework. Based on this framework, we further develop an online diagnostic toolkit that can be deployed in many organizational contexts.

The remainder of this paper is structured as follows. In the next section we review foundational literature and present the relevance and significance of this research. In section 3 we present a framework and associated diagnostic toolkit for BIA capability assessment. The fourth section outlines the design science-based methodology employed for this research. In section 5, we summarize feedback from BIA champions from the organizations in which we deployed the BIAED framework and diagnostic instrument. In the paper's final section, we present our conclusions and an assessment of our research in terms of how it conforms to Hevner et al.'s (2004) design science guidelines.

\section{Related Work}

The concept of capability maturity models has received considerable attention within the BIA field. A capability maturity model helps "integrate traditionally separate organizational functions, set process improvement goals and priorities, provide guidance for quality processes, and provide a point of reference for appraising current processes" (Chrissis et al., 2011). As a consequence, the maturity model concept has been applied to BIA initiatives to support organizations that seek to understand the current state of effectiveness or 'maturity' of BIA capabilities as a key input into defining measures to help organizations evolve to higher levels of effectiveness (Thamir and Theodoulidis, 2013). The utility of BIA-specific models has been demonstrated in several studies including Hawking (2011), Gudfinnsson et al. (2015), Fedouaki (2013), Hausladen and Hass (2014) and Rivera and Shanks (2015). These studies have shown how such models can help organizations maximize the benefits provided by BIA. In the following subsection, we provide a comprehensive review of the existing BIA capability maturity models, highlight gaps in the current research and identify the contributions of the present research.

\subsection{Review of Business Analytics Capability Maturity Models}

Numerous capability maturity models exist in the BIA literature. They span both practical and theoretical endeavors from practitioners and academics. To evaluate current models, we have leveraged the classification scheme developed by Thamir and Theodoulidis (2013), which consists of technical, organizational and human aspects, as discussed below.

\subsubsection{Technical Aspect of BIA}

As presented in Table 1, virtually all existing models (22 out of 25 models) include an assessment of the technical aspect of BIA, which includes technical infrastructure, business intelligence tools and data architecture. It is rational to assess BIA maturity from this perspective as technology provides the foundation for BIA. It is essential for organizations to invest in technical capabilities for managing data assets, delivering high quality information and providing knowledge workers with BI tools that provide the correct access and decision support functionality. This being said, it is important to note that the maturity model proposed by Williams and Williams (2007) excludes a technical assessment as the authors (who are 
business partners of the Data Warehouse Institute (TDWI)), recommend the use of TDWI's maturity assessment tool for this purpose (Rajteric, 2010).

The remaining four models in Table 1 do not consider the technical infrastructure/ tools or data architecture in their approach. Specifically, the Impact-oriented BI Maturity Model of Lahrmann et al. (2011) and the American SAP User Group's model (Hawking et al., 2010) clearly place more weight on BI tools ("Application Architecture" in the Hawking et al. (2010) model). Neither model provides a clear and explicit description of data architecture or technical infrastructure. Similarly, Chuah and Wong (2012) and SAS (2009) focus on data or information related aspects such as management, quality, policy and utilization but only vaguely refer to technical infrastructure and tools in their models.

\subsubsection{Human Aspect of BIA}

The human aspect includes BIA-related skills and knowledge, management sponsorship, training/ education and organisational culture. The majority of existing models (13 out of 25) agree on the criticality of human factors such as technical competency, experience and knowledge of BIA as well as the level of engagement, commitment and support from management in sponsoring BIA initiatives. Comparatively, the training and culture dimensions have less coverage in these models, (only 6 of 25 models). It is worth noting that only two models - Davenport and Harris' (2007) Analytical Capability Maturity Model and the Cosic et al. (2012) BIACMM- cover all four dimensions of the human aspect. Three models exclude the human aspect in their model constructs: the American SAP User Group (Hawking et al., 2010), biMM (SMC, 2009) and Organic BI Evolution Model (Russell et al., 2010). Notably, the Russell et al. (2010) Organic BI Evolution Model of is biologically inspired and attempts to mimic the evolution of life. This model focuses entirely on the technical aspect of BIA and consists of four stages (conception, coalescence, saturation and diversification) with each stage described by five levels.

The other reviewed models present one to three human factors. For example, the EBIM Model (Tan et al., 2011), Data Warehousing Stages of Growth (Watson et al., 2009), BI Maturity Model (Williams and Williams, 2007), Infrastructure Optimization Maturity Model (Microsoft, 2007), BI Maturity Hierarchy (Deng, 2007) TERADATA Maturity Model (Miller et al., 2009), BI Development Model (Sacu and Spruit, 2010) present one human factor. Other models include two dimensions, for instance, BIMM (Raber et al., 2012), BI Maturity Model for Healthcare (Brooks et al., 2015), Enterprise Data Management Maturity Model (Fisher, 2007), Hewlett Packard BI Maturity Model (HP, 2009), the Impact-Oriented BI Maturity Model (Lahrmann et al., 2011) and The BI Maturity Model (Stock, 2013) have taken both skills and sponsorship into account in their models. Three models cover three human aspect dimensions: Gartner's Maturity Model (Rayner and Schlegel, 2008), SAS' Information Evolution Model (SAS, 2009) and the Data Warehousing Process Maturity Model (Sen et al., 2006).

\subsubsection{Organizational Aspect of BIA}

The 25 models we reviewed reveal a total of four organizational dimensions. In particular, 16 of the reviewed models cover analytical processes, 13 models include organizational structure, 15 models capture governance and 10 models embrace the concept of cost-benefit analysis. TDWI's BI Maturity Model (Eckerson, 2009) and Stock's (2013) BI Maturity Model cover all four organizational dimensions. Conversely, the Organic BI Evolution Model (Russell et al., 2010) and BI Maturity Model for Healthcare (Brooks et al., 2015) do not explicitly address organizational factors in their models. The Brooks et al. (2015) model includes vision and strategy as well as management engagement and support, but group these factors under the human aspect of BIA.

The remaining models cover one to three organizational dimensions as depicted in Table 1. There are seven models that capture only one dimension, namely the EBIM Model (Tan et al., 2011), Data Warehousing Stages of Growth (Watson et al., 2001), Data Warehousing Process Maturity (Sen et al., 2006), Enterprise Data Management Maturity Model (Fisher, 2007), 
Infrastructure Optimization Maturity Model (Microsoft, 2007), Analytical Capability Maturity Model (Davenport and Harris, 2007) and BI Maturity Hierarchy (Deng, 2007). Tan et al. (2011), Sen et al. (2006) and Fisher (2007) include governance as part of their model design. Furthermore, Deng (2007), Microsoft (2007) and Watson et al. (2001) include cost-benefit analysis as a maturity model construct. The models proposed by Hagerty (2006), SAS (2009), SMC (2009) and Sacu and Sprui (2010) embrace two dimensions: analytical processes and organizational structure. The remaining models have considered three dimensions in their model design.

To summarize, our review of existing maturity models provides us with many BIA maturity evaluation dimensions. However, we have also identified shortcomings in existing BIA maturity models and subsequently propose to address significant research gaps in this particular area.

\begin{tabular}{|c|c|c|c|c|c|c|c|c|c|c|c|}
\hline \multirow{3}{*}{$\begin{array}{l}\text { No } \\
\cdot\end{array}$} & \multirow{3}{*}{$\begin{array}{l}\text { BI Maturity Models with } \\
\text { References }\end{array}$} & \multicolumn{10}{|c|}{ Maturity Aspects and Dimensions } \\
\hline & & \multicolumn{4}{|c|}{ Organizational } & \multicolumn{4}{|c|}{ Human } & \multicolumn{2}{|c|}{ Technical } \\
\hline & & 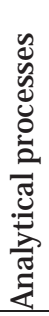 & 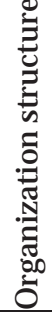 & 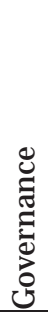 & $\begin{array}{l}3 \\
\frac{3}{0} \\
\frac{1}{0} \\
\frac{0}{1} \\
\frac{1}{80} \\
0\end{array}$ & 帚 & 串 & 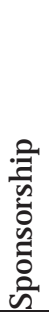 & 莺 & 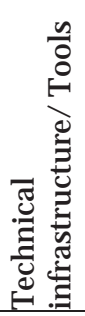 & 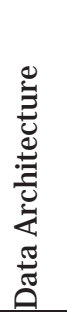 \\
\hline 1 & $\begin{array}{l}\text { The BI Maturity Model (Stock, } \\
\text { 2013) }\end{array}$ & $\mathrm{X}$ & $\mathrm{X}$ & $\mathrm{X}$ & $\mathrm{x}$ & $\mathrm{x}$ & & $\mathrm{X}$ & & $\mathrm{X}$ & $\mathrm{X}$ \\
\hline 2 & $\begin{array}{l}\text { Enterprise Business } \\
\text { Intelligence Maturity Model } \\
\text { (Chuah and Wong, 2012) }\end{array}$ & $\mathrm{X}$ & $\mathrm{X}$ & $\mathrm{X}$ & & $\mathrm{X}$ & & & & & $\mathrm{X}$ \\
\hline 3 & $\begin{array}{l}\text { Impact-Oriented BI Maturity } \\
\text { Model (Lahrmann et al., 2011) }\end{array}$ & $\mathrm{X}$ & & $\mathrm{X}$ & $\mathrm{X}$ & $\mathrm{X}$ & & $\mathrm{X}$ & & $\mathrm{X}$ & \\
\hline 4 & $\begin{array}{l}\text { American SAP User Group } \\
\text { (Hawking et al., 2010) }\end{array}$ & $\mathrm{X}$ & $\mathrm{X}$ & $\mathrm{X}$ & & & & & & $\mathrm{X}$ & \\
\hline 5 & $\begin{array}{l}\text { Business Intelligence } \\
\text { Development Model (Sacu and } \\
\text { Spruit, 2010) }\end{array}$ & $\mathrm{X}$ & $\mathrm{X}$ & & & & & & $\mathrm{X}$ & $\mathrm{X}$ & $\mathrm{X}$ \\
\hline 6 & $\begin{array}{l}\text { TERADATA's BI and DW } \\
\text { Maturity Model (Miller et al., } \\
\text { 2009) }\end{array}$ & $\mathrm{X}$ & & $\mathrm{X}$ & $\mathrm{x}$ & & $\mathrm{x}$ & & & $\mathrm{X}$ & $\mathrm{X}$ \\
\hline 7 & $\begin{array}{l}\text { TDWI's BI Maturity Model } \\
\text { (Eckerson, 2009) }\end{array}$ & $\mathrm{X}$ & $\mathrm{X}$ & $\mathrm{X}$ & $\mathrm{x}$ & & & $\mathrm{X}$ & $\mathrm{X}$ & $\mathrm{X}$ & $\mathrm{X}$ \\
\hline 8 & $\begin{array}{l}\text { Hewlett Packard BI Maturity } \\
\text { Model (HP, 2009) }\end{array}$ & $\mathrm{X}$ & $\mathrm{X}$ & $\mathrm{X}$ & & $\mathrm{X}$ & & $\mathrm{X}$ & & $\mathrm{X}$ & $\mathrm{X}$ \\
\hline 9 & $\begin{array}{l}\text { biMM Steria Mummert } \\
\text { Consulting (SMC, 2009) }\end{array}$ & $\mathrm{X}$ & $\mathrm{X}$ & & $\mathrm{X}$ & & & & & $\mathrm{X}$ & $\mathrm{X}$ \\
\hline 10 & $\begin{array}{l}\text { Gartner Maturity Model for } \\
\text { Business Intelligence and } \\
\text { Performance Management } \\
\text { (Rayner and Schlegel, 2008) }\end{array}$ & $\mathrm{X}$ & $\mathrm{X}$ & $\mathrm{X}$ & & & $\mathrm{X}$ & $\mathrm{X}$ & $\mathrm{X}$ & $\mathrm{X}$ & $\mathrm{X}$ \\
\hline 11 & $\begin{array}{l}\text { SAS Information Evolution } \\
\text { Model (SAS, 2009) }\end{array}$ & $\mathrm{X}$ & $\mathrm{X}$ & & & $\mathrm{X}$ & $\mathrm{X}$ & & $\mathrm{X}$ & & $\mathrm{X}$ \\
\hline 12 & $\begin{array}{l}\text { Business Intelligence Maturity } \\
\text { Hierarchy (Deng, 2007) }\end{array}$ & & & & $\mathrm{X}$ & $\mathrm{X}$ & & & & $\mathrm{X}$ & $\mathrm{X}$ \\
\hline
\end{tabular}




\begin{tabular}{|c|c|c|c|c|c|c|c|c|c|c|c|}
\hline 13 & $\begin{array}{l}\text { Analytical Capability Maturity } \\
\text { Model (Davenport and Harris, } \\
\text { 2007) }\end{array}$ & $\mathrm{X}$ & & & & $\mathrm{X}$ & $\mathrm{X}$ & $\mathrm{X}$ & $\mathrm{X}$ & $\mathrm{X}$ & $\mathrm{X}$ \\
\hline 14 & $\begin{array}{l}\text { Infrastructure Optimization } \\
\text { Maturity Model (Microsoft, } \\
\text { 2007) }\end{array}$ & & & & $\mathrm{X}$ & & & & $\mathrm{X}$ & $\mathrm{X}$ & $\mathrm{X}$ \\
\hline 15 & $\begin{array}{l}\text { Enterprise Data Management } \\
\text { Maturity Model (Fisher, 2007) }\end{array}$ & & & $\mathrm{X}$ & & $\mathrm{X}$ & & $\mathrm{X}$ & & $\mathrm{X}$ & $\mathrm{X}$ \\
\hline 16 & $\begin{array}{l}\text { Business Intelligence Maturity } \\
\text { Model (Williams and Williams, } \\
\text { 2007) }\end{array}$ & $\mathrm{X}$ & & $\mathrm{X}$ & $\mathrm{X}$ & & & & $\mathrm{X}$ & & \\
\hline 17 & $\begin{array}{l}\text { Data Warehousing Process } \\
\text { Maturity (Sen et al., 2006) }\end{array}$ & & & $\mathrm{X}$ & & $\mathrm{X}$ & $\mathrm{X}$ & & $\mathrm{X}$ & $\mathrm{X}$ & $\mathrm{X}$ \\
\hline 18 & $\begin{array}{l}\text { AMR Research's Business } \\
\text { Intelligence / Performance } \\
\text { Management Maturity Model } \\
\text { (Hagerty, 2006) }\end{array}$ & $\mathrm{X}$ & $\mathrm{X}$ & & & & & $\mathrm{X}$ & $\mathrm{X}$ & $\mathrm{X}$ & $\mathrm{X}$ \\
\hline 19 & $\begin{array}{l}\text { Ladder of Business } \\
\text { Intelligence (Cates et al., 2005) }\end{array}$ & $\mathrm{X}$ & $\mathrm{X}$ & $\mathrm{X}$ & & & & $\mathrm{X}$ & & $\mathrm{X}$ & $\mathrm{X}$ \\
\hline 20 & $\begin{array}{l}\text { Data Warehousing stages of } \\
\text { growth (Watson et al., 2001) }\end{array}$ & & & & $\mathrm{X}$ & $\mathrm{X}$ & & & & $\mathrm{X}$ & $\mathrm{X}$ \\
\hline 21 & BIACMM (Cosic et al., 2012) & $\mathrm{X}$ & $\mathrm{X}$ & $\mathrm{X}$ & & $\mathrm{X}$ & $\mathrm{X}$ & $\mathrm{X}$ & $\mathrm{X}$ & $\mathrm{X}$ & $\mathrm{X}$ \\
\hline 22 & $\begin{array}{l}\text { Organic Evolution of BI } \\
\text { (Russell et al., 2010) }\end{array}$ & & & & & & & & & $\mathrm{X}$ & $\mathrm{X}$ \\
\hline 23 & $\begin{array}{l}\text { Enterprise BI Maturity (EBIM) } \\
\text { Model (Tan et al., 2011) }\end{array}$ & & & $\mathrm{X}$ & & & & $\mathrm{X}$ & & $\mathrm{X}$ & $\mathrm{X}$ \\
\hline 24 & BIMM (Raber et al., 2012) & & $\mathrm{X}$ & $\mathrm{X}$ & $\mathrm{X}$ & $\mathrm{X}$ & & $\mathrm{X}$ & & $\mathrm{X}$ & $\mathrm{X}$ \\
\hline 25 & $\begin{array}{l}\text { BI Maturity Model for } \\
\text { Healthcare (Brooks et al., } \\
\text { 2015) }\end{array}$ & & & & & $\mathrm{X}$ & & $\mathrm{X}$ & & $\mathrm{X}$ & $\mathrm{X}$ \\
\hline & Total number & 16 & 13 & 15 & 10 & 13 & 6 & 14 & 10 & 22 & 22 \\
\hline
\end{tabular}

Table 1. Review of existing BIA capabilities maturity models (adapted from Thamir and Theodoulidis, 2013)

\subsection{Research gap and contributions}

While researchers have proposed numerous BIA maturity models, to date there has been limited research on how they should be operationalized, i.e., clearly defining how organizations can deploy such models to guide the ongoing maturation of their BIA capabilities in a comprehensive and systematic way. Prior studies have focused exclusively on BIA model substance - i.e., the aspects of maturity to be assessed. Previous studies pay little attention to two important factors, specifically, the process context for maturity assessment, and the constituencies (i.e. stakeholders) whose input must be sought. Considering the process context is critical because BIA assessments must seamlessly align with IT and business strategy development processes. If assessments are done in isolation, results cannot be effectively leveraged to organizational advantage, regardless of the quality of the framework employed. Further, an organization's BIA capabilities will have strengths and weaknesses, thus there is a critical need to understand the nature of these strengths and weaknesses as perceived by key stakeholder groups: individuals who use (BIA end-users), provide technical support for (IT personnel) and fund (senior management) BIA initiatives.

It is surprising that none of the models reviewed consider the process context and the constituencies at the operationalization level. Therefore this research fills a significant research 
gap by providing a more comprehensive BIA effectiveness diagnostic (BIAED) framework that considers people and process in addition to the substance of the assessment.

Along these lines, we employ a design science paradigm and develop a BIAED framework that explicitly considers assessment content, process context and key constituents. Drawing on the BIAED framework, we further develop an online diagnostic toolkit. Specifically, the toolkit includes a custom-developed software application that allows the creation and administration of specialized online survey instruments and an extensive library of survey categories and over 300 questions (available at: https:// goo.gl/ bmP18d). Subsequently, we deploy and iteratively evolve the framework and toolkit in three North America-based organizations in order to validate their utility and practicality.

In terms of research contributions, this paper addresses an important topic in the field of business intelligence and analytics, that is, the operationalization of effectiveness/maturity analysis. We develop a framework that represents a practical and useful approach for assessing the current state of BIA capabilities and for using the assessment results to drive strategy development. Weidentify the stakeholder groups to be consulted (i.e., BIA end-users, technical personnel and senior management), and concisely specify the informational input required from each group. From a practical perspective, this research provides an efficient approach and toolkit that can be readily operationalized by any organization to assess BIA effectiveness in order to drive moving-forward strategies.

\section{Developing the Organizational BIA Effectiveness Diagnostic Mechanism}

The following sub-sections outline and present the details of the BIAED framework that is composed of three components: assessment dimensions, constituencies to be consulted and process context.

\subsection{Assessment Dimensions}

An effective assessment of BIA capabilities requires that the proper elements be analyzed. As presented in Figure 1, we view the dimensions of BIA maturity as falling into two broad categories of what we term "Management Levers" - factors that can be controlled and manipulated to increase BIA effectiveness. We submit that effectively manipulating these levers, i.e., through the development of BIA-related strategies and associated tactics positively influences BIA system users' perceptions of the value of the BIA system in terms of its support for analysis and decision-making. High levels of perceived value leads to extensive use of the system (as measured by frequency and duration use as well as the level of emersion), which in turn provides individual and ultimately organizational benefits. Given the difficulty of quantifying the organizational benefits that result from effective BIA capabilities (benefits tend to be second and third order effects), our framework focuses on assessing perceived individual benefits as well as level of BIA system use. 


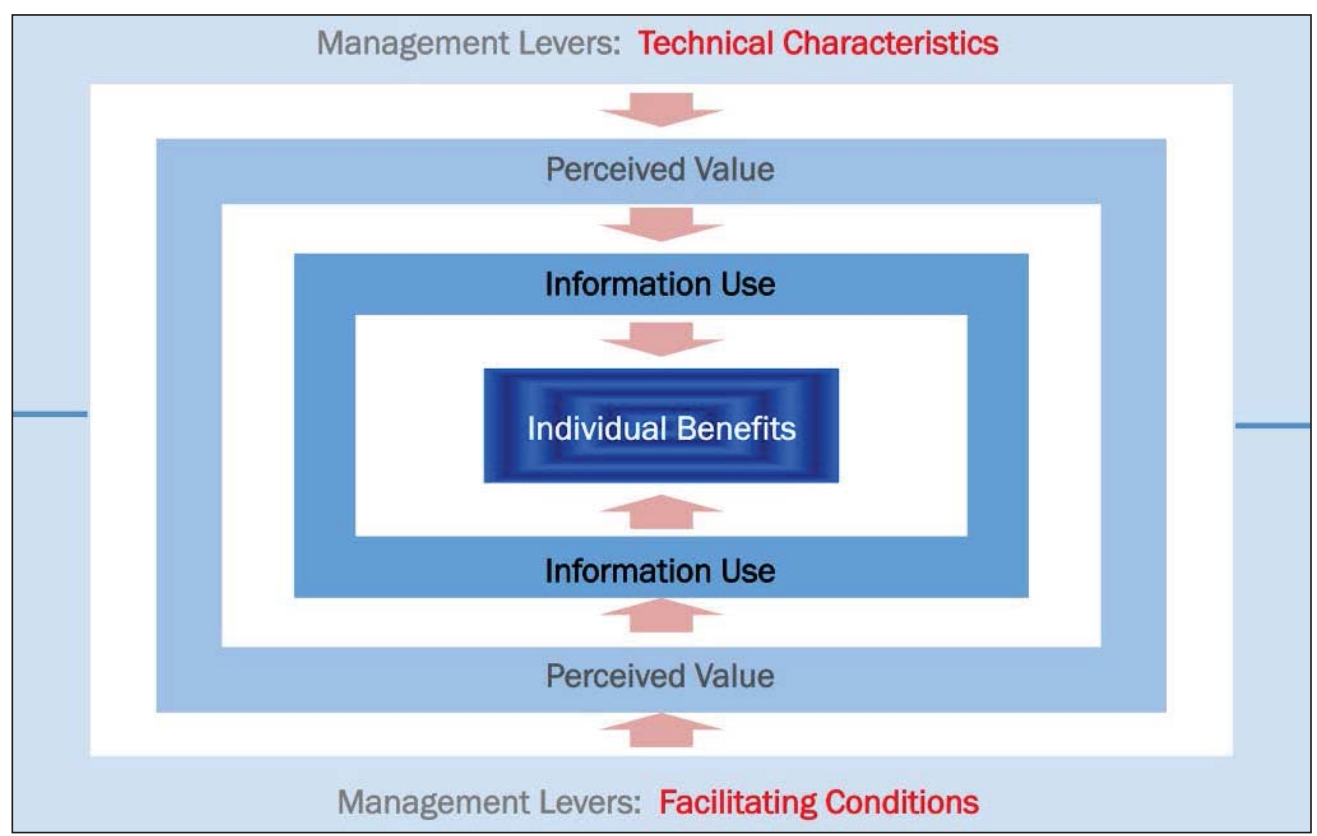

Figure 1. BIA Effectiveness Assessment Model

Based on our review of the extant literature on BIA maturity models, we propose Technical Characteristics ( $\mathrm{sec}$ 3.1.1) and Facilitating Conditions (sec 3.1.2) as the two primary categories of Management Levers. Technical characteristics assess the nature/ quality of the data, metadata, BI tools and applications as well as the technical infrastructure supporting BIA. Facilitating Conditions span and add granularity to the organizational and human maturity aspects proposed by Thamir and Theodoulidis (2013) and include the following dimensions: organizational culture and management support, process integration, delivery methodology, skills and knowledge and IT support and training. The dimensions of each category as well as the rationale explaining their necessity are detailed in the following two sections.

\subsubsection{Technical Characteristics}

Data Quality: High levels of data quality, as measured by dimensions such as accuracy, completeness, clarity and relevance is a fundamental building block of BIA systems. The measurement of data quality should be based on user perceptions (vs. absolutemeasures). This is due to the fact that users must perceive the data presented to them as being of sufficient quality to be useful to them in carrying out job functions - data must 'fit its purpose' (Wang and Strong, 1996).

Metadata Quality: Metadata is best described as information about the information resources available from BIA systems. Metadata is an essential support for users who must understand the information available in order to trust and use it. The presence of metadata improves decision process efficiency as well as decision quality (Shankaranarayanan et al., 2006). When metadata is not available, users have been observed to avoid using a BI system (Watson and Haley, 1998). Foshay et al. (2014) propose that BIA systems should provide four types of metadata: definitional, quality, lineage and navigational and that metadata ensures that users are knowledgeable of and comfortable with the information supplied by BIA systems.

Tools and Applications: BIA systems must support a wide array of BIA 'use cases', including improving overall corporate performance, improving existing and enabling new processes and competencies and supporting collaboration both internally and externally (Huang et al., 2012). As such, the tools and applications (e.g., reports, models, dashboards and scorecards) enabling BIA must meet a wide array of needs. Further, BI tools must provide the correct functionality, level of access, interactivity and performance required by users (Verkooij and Spruit, 2011; Sharma and Djiaw, 2011). 
Technical Infrastructure: A key characteristic of effective BIA systems is their ability to adapt to ever changing user needs and to scale rapidly in the face of increasing activity and complexity (Thamir and Theodoulidis 2013). This necessitates careful planning and investment and the deployment of a robust data and system architecture. Data architecture refers to the manner in which data is organized and stored to support BIA applications. Effective data architectures provide a balance of central management and user-oriented data provisioning as well as robust models for master data management (MDM). System architecture focuses on the flexibility, reliability, suitability, and effectiveness of the tools and processes leveraged to build and maintain BI system infrastructure and include Extract, Transform and Load (ETL), data cleansing, metadata management and MDM tools and processes (Olszak and Ziemba, 2007; Sen et al., 2012).

\subsubsection{Facilitating Conditions}

Organizational Culture and Management Support: In order for BIA to be effectively disseminated throughout an organization, an 'information oriented' culture is essential (Marchand et al., 2000). This means that a fact-driven approach to decision making is accepted as a corporate norm and that appropriate enterprise-level financial investments are made in people (training and education), processes and technology to ensure that this is the case. Further, the active and visible support of senior management is a key element of a mature information-oriented culture (Popovic et al., 2012).

Organizational Alignment and Process Integration: BIA systems must provide organizations with an effective means to sense and respond to what is happening in both external and operational environments (Kettinger and Marchand, 2011). As such, organizations require robust analytic processes to be in place and aligned with strategy development and performance management efforts (Hawking and Sellitto, 2015; Schläfke et al., 2012). Further, BIA must be embedded in in organizational business processes in order to monitor and measure organizational performance at multiple levels (Sharma and Djiaw, 2011; Bucher et al., 2009).

BIA Practices/Development Approach: The nature of the systems that support BIA differs significantly from other types of information systems given their informational (vs. functional) focus. Further, they include elements of both infrastructure (i.e., ETL process development and data warehouse deployment) and user-focused applications (e.g., reports, dashboards, scorecards and cubes) (Lahrmann et al., 2011). As such, organizations must develop strong capabilities in BIA-specific practices (i.e., a process framework as well as tools and techniques) that address the uniqueness of BIA system delivery and to ensure effective, consistent, and repeatable implementations (Couture, 2013).

BIA-related Skills and knowledge: Organizations require both strong technical skills for the delivery of BIA systems as well as business analytics skills on the part of business personnel (Chuah and Wong, 2011). As such, it is essential to understand the degree to which specific BIA roles are defined within an organization and the training and education that is available to ensure that appropriate skills and knowledge are developed and enhanced (Stock, 2013).

Data governance: Data quality is a cornerstone of BIA. As such, organizations require effective data governance processes, people and tools (e.g., metadata management, data profiling, etc.) to ensure that important data assets are formally managed throughout the enterprise (Eckerson, 2007).

Project governance: Many organizations suffer from a large backlog of BIA-oriented projects. As such, it is essential that the BIA resources be deployed in a way that ensures alignment with organizational priorities. This implies that there exists effective BIA project governance: processes, decision frameworks, roles and tools to identify, define and prioritize BIA projects in a manner that aligns solution delivery with business strategy and priorities (Barrett and Barton, 2006). 


\subsection{Constituencies}

In order to obtain a true picture of the current state of BIA effectiveness, we propose that input must be sought from three distinct groups (i.e. constituencies) within an organization: BIA users, the technical team, and senior management. Each group has a unique perspective that must be considered in order to understand the degree to which BIA is having the desired impact within an organization. BIA users are the consumers of the information resources provided by BIA systems. They are organizational decision makers and the knowledge workers who support them. The technical team is responsible for the architecture, design, delivery and ongoing support of BIA solutions. Senior management personnel (who may also be BIA users) provide funding and, perhaps more importantly, establish the organization's culture regarding the importance of BIA and data driven decision-making.

An effective stakeholder engagement process employs a variety of information gathering techniques including surveys, interviews/focus groups and workshops. The informational inputs that should be solicited from each group are presented in Table 2.

\begin{tabular}{|c|c|c|c|}
\hline Evaluation Dimension & Users & $\begin{array}{l}\text { Technical } \\
\text { Team }\end{array}$ & $\begin{array}{c}\text { Senior } \\
\text { Management }\end{array}$ \\
\hline \multicolumn{4}{|c|}{ Technical Characteristics } \\
\hline Data quality & $\mathrm{X}$ & $\mathrm{X}$ & \\
\hline Metadata quality & $\mathrm{X}$ & & \\
\hline BIA tools and applications & $\mathrm{X}$ & & \\
\hline Technical infrastructure & & $\mathrm{X}$ & \\
\hline \multicolumn{4}{|c|}{ Facilitating Conditions } \\
\hline Organizational culture and management support & $\mathrm{X}$ & $\mathrm{X}$ & $\mathrm{X}$ \\
\hline Organizational alignment and process integration & $\mathrm{X}$ & & $\mathrm{X}$ \\
\hline BIA practices/ development approach & $\mathrm{X}$ & $\mathrm{X}$ & \\
\hline BIA-related skills and knowledge & $\mathrm{X}$ & $\mathrm{X}$ & $\mathrm{X}$ \\
\hline Data governance & $\mathrm{X}$ & $\mathrm{X}$ & \\
\hline Project governance & & $\mathrm{X}$ & $\mathrm{X}$ \\
\hline \multicolumn{4}{|c|}{ Outcomes } \\
\hline Perceived value & $\mathrm{X}$ & & $\mathrm{X}$ \\
\hline Level of use & $\mathrm{X}$ & $\mathrm{X}$ & \\
\hline
\end{tabular}

Table 2. Information required from each constituency group

As highlighted by Table 2, input for a given evaluation dimension may be sought from multiple constituencies - e.g., from both BIA users and the technical team. There are a number of reasons for this, but one key purpose is to determine if there is significant misalignment of views between groups. For example, the technical team may believe that data quality in BIA systems is good, based on their empirical analysis. However, BIA users may have a different perception based on the fitness-to-purpose of this data. Where misalignment is identified, measures can be established to address.

\subsection{Process Context}

It is important for organizations to regularly assess the effectiveness of BIA capabilities in order to ensure that they evolve at an optimal pace (Hawking and Sellitto, 2015). Such assessments cannot be standalone or academic exercises - an organization must be positioned to take action on the insights gained. This means that organizations must perform assessments in the proper context - i.e., that provided by a strategy development process, as outlined in Figure 2.

We propose that the first step in such a process is a thorough assessment of BIA capability effectiveness. As previously stated, the assessment exercise must evaluate all relevant capability dimensions and ensure that input is collected from the proper constituencies. 


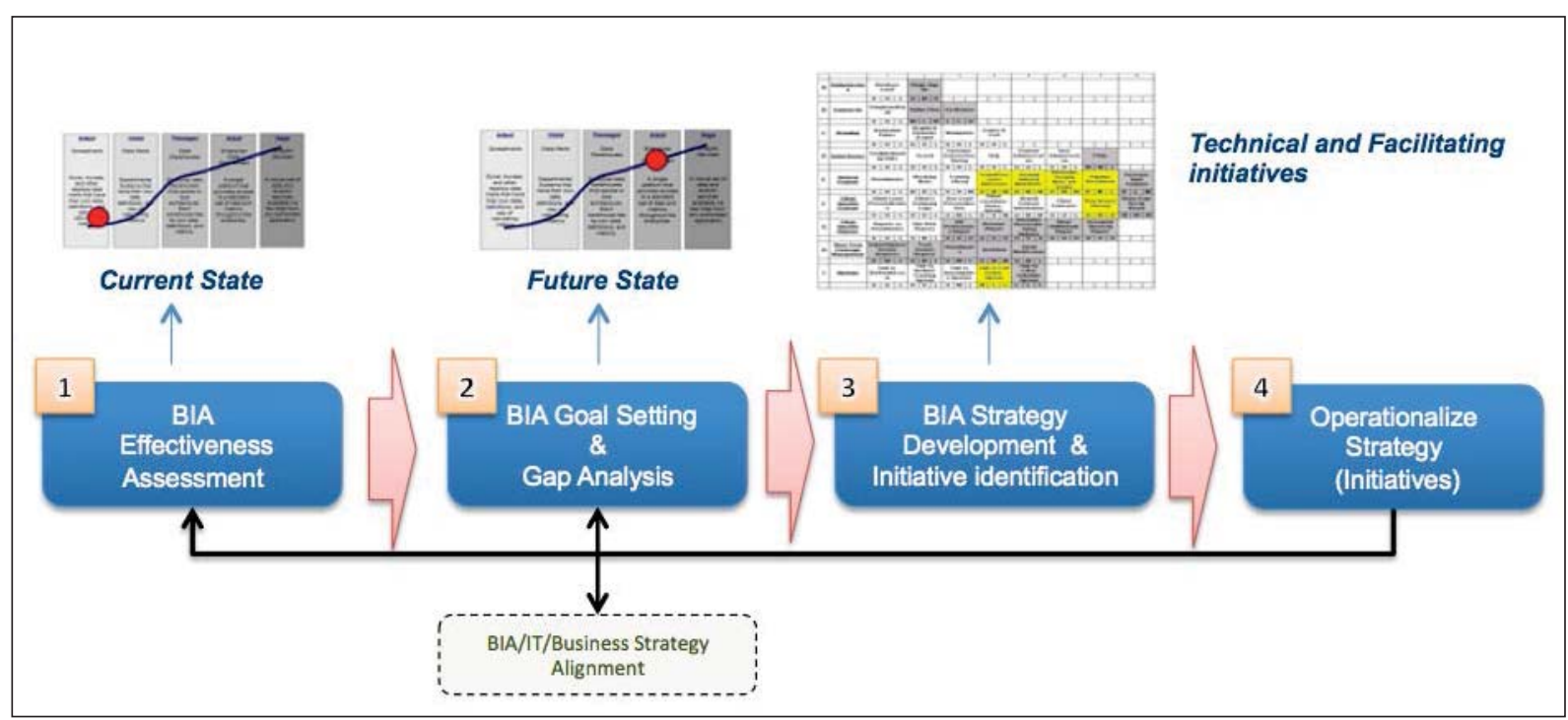

Figure 2. BIA strategy development process

The assessment serves as a critical input into the second step of the process - Goal Setting and Gap Analysis. In this step, insights gained from the current state assessment are factored along with BIA best practices and the organization's IT and business strategy to identify and prioritize BIA goals over a specific time horizon and clearly identify gaps in current capabilities (as identified in step 1) that may hinder their achievement. With goals and gaps identified, the organization can develop its BIA strategy and identify and prioritize specific initiatives to operationalize thestrategy (step 3). In the final step, the group(s) responsible for BIA can begin executing initiatives that operationalize strategy and move the organization towards its goals. We propose that BIA initiatives fall into two broad categories - BIA application delivery and BIA process and infrastructure development. The former category involves delivering new or significantly enhancing BIA applications while the latter may have an array of goals including improving technical infrastructure, addressing data quality issues, increasing the skill and knowledge level of technical and business personnel and enhancing analytic and decision processes. Our proposed process is iterative and ongoing - after a period of time, the effectiveness of the initiatives undertaken must be measured by starting the process again through a BIA effectiveness assessment (step 1).

The information collected during the assessment must be actionable to be useful. This has significant implications for its characteristics. Specifically, the unit of analysis must be clearly defined and the information captured regarding the unit of analysis must be sufficiently granular as to be directional. The unit of analysis refers to the specific BIA 'ecosystem' that is to be assessed (i.e., BIA applications, underlying infrastructure and business areas supported). In many large organizations a number of BIA systems may exist, each at a different level of maturity. As such, when performing a maturity assessment, the scope of the assessment must be clearly defined and communicated to the constituents who will be participating.

Granularity refers to the level of detail captured. The data collected must play two roles. First, it must clearly describe the maturity or effectiveness of each assessment dimension on a well-defined scale or continuum. This allows progress to be benchmarked and measured over time. Second, the data collected must provide actionable insights; it must help explain why the current state of a given assessment dimension exists. Consider the following example. The quality of data, as perceived by BIA system users, is an important feature or characteristic of a BIA system. To assess the current state, data regarding user perceptions of data quality must be collected, with a focus on its fitness to purpose. Further, where there are perceived quality issues, the nature of the defects must be identified so that they can be addressed. Figure 3 presents a set of questions that serve both roles. The Likert style questions allow perceptions of quality in the unit of analysis (e.g. a data warehouse) to be quantified. The guided, openended questions permit specific issues, and the impact of these issues, to be described. 


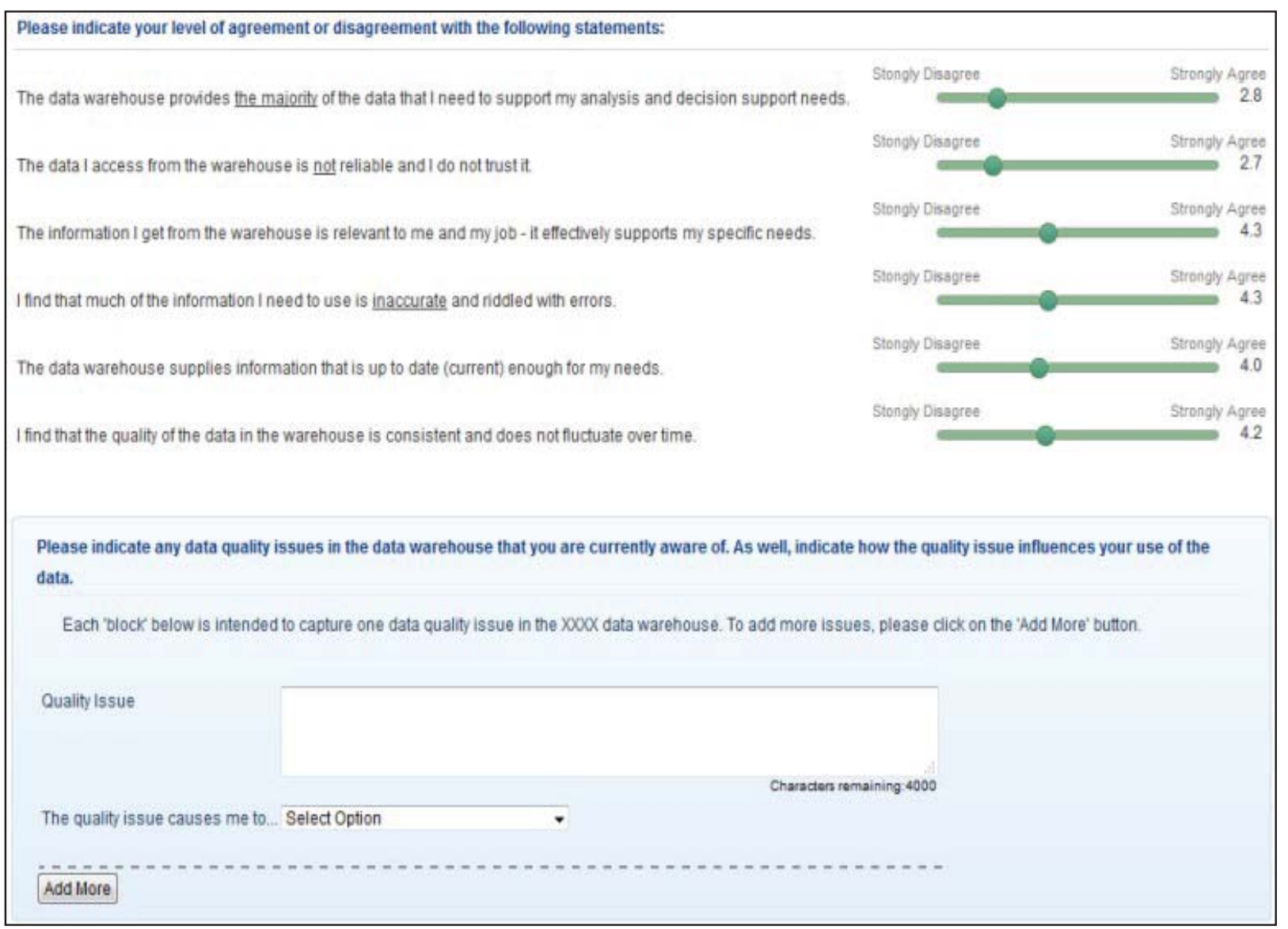

Figure 3. Survey question example

\section{Methodology}

This research employs Hevner et al.'s (2004) design science paradigm - an approach to scientific inquiry in which researchers seek to address specific organizational issues through the creation and evaluation of innovative IT artefacts. Design science has been an important paradigm in decision support systems (DSS) research (Arnott and Pervan, 2012), an area in which this paper also belongs. According to Hevner et al., the objective of design science is to create artefacts (broadly defined to include constructs, models, methods, and instantiations) that have utility. Our research develops and evaluates two such artefacts: an organizational BIA effectiveness diagnostic framework and an associated online diagnostic toolkit. Our objectives are aligned with those of design science - to provide a practical and useful means to evaluate an organization's BIA capabilities in order to improve them.

As proposed by Hevner et al. (2004), there are seven fundamental guidelines for design science research required to understand the problem to be solved and to design and deploy an artefact to address the problem. The approach dictates that a) a new artefact should be created and b) that it should provide a novel solution to an important business problem in particular domain (e.g., DSS) (Arnott and Pervan, 2012). A valid artefact requires exhaustive evaluation of its utility, quality and effectiveness in addressing a problem. Any design science research must make a clearly defined contribution to the literature in the form of a new artefact, creation of foundational elements or methodological advances and must be developed and evaluated utilizing rigorous methods. Developing optimal artefacts must be an iterative process. Finally, it is essential to effectively communicate research outcomes to both technical and managerial audiences. Table 3 depicts Hevner's (2004) guidelines for design science research and describes how our research process successfully conforms to these guidelines. 


\begin{tabular}{|c|c|c|}
\hline Guideline & $\begin{array}{c}\text { Hevner et al.'s (2004) } \\
\text { description }\end{array}$ & Mapping to this research \\
\hline $\begin{array}{l}\text { Guideline 1: Design } \\
\text { as an Artefact }\end{array}$ & $\begin{array}{l}\text { Design-science research must produce } \\
\text { a viable artefact in the form of a } \\
\text { construct, a model, a method, or an } \\
\text { instantiation. }\end{array}$ & $\begin{array}{l}\text { Our project designs and delivers two artefacts: a } \\
\text { BIAED framework and a comprehensive online } \\
\text { diagnostic toolkit. }\end{array}$ \\
\hline $\begin{array}{l}\text { Guideline 2: } \\
\text { Problem Relevance }\end{array}$ & $\begin{array}{l}\text { The objective of design-science } \\
\text { research is to develop technology- } \\
\text { based solutions to important and } \\
\text { relevant business problems. }\end{array}$ & $\begin{array}{l}\text { This paper addresses a significant business issue: } \\
\text { assessing the current strengths and weaknesses of } \\
\text { BIA capabilities, thus providing key insights to } \\
\text { drive future strategy / investment that increases } \\
\text { BIA effectiveness. }\end{array}$ \\
\hline $\begin{array}{l}\text { Guideline 3: } \\
\text { Design Evaluation }\end{array}$ & $\begin{array}{l}\text { The utility, quality, and efficacy of a } \\
\text { design artefact must be rigorously } \\
\text { demonstrated via well-executed } \\
\text { evaluation methods. }\end{array}$ & $\begin{array}{l}\text { The framework and the diagnostic toolkit were } \\
\text { designed and subsequently deployed and } \\
\text { evaluated in three organizations (involving over } \\
1500 \text { participants). Feedback was solicited from } \\
\text { technical and business personnel and } \\
\text { incorporated into our artefact design. }\end{array}$ \\
\hline $\begin{array}{l}\text { Guideline 4: } \\
\text { Research } \\
\text { Contributions }\end{array}$ & $\begin{array}{l}\text { Effective design-science research must } \\
\text { provide clear and verifiable } \\
\text { contributions in the areas of the } \\
\text { design artefact, design foundations, } \\
\text { and/ or design methodologies. }\end{array}$ & $\begin{array}{l}\text { The two designed artefacts (i.e. the BIAED } \\
\text { framework and the associated online diagnostic } \\
\text { toolkit) represent the research contributions. Our } \\
\text { work furthers research in the area of BIA } \\
\text { effectiveness/maturity assessment by providing } \\
\text { operationalizable artefacts designed to support } \\
\text { BIA strategy development. }\end{array}$ \\
\hline $\begin{array}{l}\text { Guideline 5: } \\
\text { Research Rigor }\end{array}$ & $\begin{array}{l}\text { Design-science research relies upon } \\
\text { the application of rigorous methods in } \\
\text { both the construction and evaluation } \\
\text { of the design artefact. }\end{array}$ & $\begin{array}{l}\text { The two artefacts developed were rigorously } \\
\text { constructed based on an extensive literature } \\
\text { review and subsequently tested, deployed and } \\
\text { evaluated within three organizations. }\end{array}$ \\
\hline $\begin{array}{l}\text { Guideline 6: } \\
\text { Design as a Search } \\
\text { Process }\end{array}$ & $\begin{array}{l}\text { The search for an effective artefact } \\
\text { requires utilizing available means to } \\
\text { research desired ends while satisfying } \\
\text { laws in the problem environment. }\end{array}$ & $\begin{array}{l}\text { The artefacts were grounded in existing literature } \\
\text { then iteratively pilot-tested within participating } \\
\text { organizations taking into consideration the } \\
\text { practical concerns and constraints of each } \\
\text { organization. }\end{array}$ \\
\hline $\begin{array}{l}\text { Guideline 7: } \\
\text { Communication of } \\
\text { Research }\end{array}$ & $\begin{array}{l}\text { Design-science research must be } \\
\text { presented effectively both to } \\
\text { technology-oriented as well as } \\
\text { management-oriented audiences. }\end{array}$ & $\begin{array}{l}\text { The BIAED framework, the diagnostic toolset and } \\
\text { the information gained through assessments were } \\
\text { presented to technical and business stakeholders } \\
\text { within participating organizations. }\end{array}$ \\
\hline
\end{tabular}

Table 3. The mapping of BIAED framework to design science research guidelines (adopted from Hevner et al., 2004)

We initiated our research by conducting a comprehensive review of the existing literature regarding BIA maturity and effectiveness assessment, as detailed sections 2 and 3. Based on our review, we conceived the BIAED framework and developed a preliminary edition of our diagnostic instruments. We then determined that the optimal approach to evaluate and optimize our design was through a series of organizational case studies. To this end, we approached three North American organizations, a Canadian municipal government (i.e., the Halifax Regional Municipality in Nova Scotia), a Canadian government agency known as the Property Valuation Services Corporation (PVSC), and a large multi-national automobile manufacturer (to comply with the agreement made with this organization, the name of the company is kept confidential). Table 4 presents an overview of each organization, as well as their BIA assessment goals. 


\begin{tabular}{|l|c|l|}
\hline \multicolumn{1}{|c|}{ Organization } & \multicolumn{1}{|c|}{$\begin{array}{c}\text { Number of } \\
\text { participants }\end{array}$} & \multicolumn{1}{c|}{ Organizational Overview } \\
\hline $\begin{array}{l}\text { International } \\
\text { automobile } \\
\text { manufacturer }\end{array}$ & 1050 & $\begin{array}{l}\text { This large international automobile manufacturer sought to } \\
\text { evaluate the BIA capabilities supporting all of their North } \\
\text { American business units. The organization had previously made } \\
\text { large-scale investments in BIA tools, technology infrastructure } \\
\text { and personnel. The organization looked to gain an } \\
\text { understanding of key factors currently limiting BIA adoption } \\
\text { across business units in order to develop moving-forward } \\
\text { strategies. }\end{array}$ \\
\hline $\begin{array}{l}\text { Halifax Regional } \\
\text { Municipality }\end{array}$ & 300 & $\begin{array}{l}\text { This municipality based in eastern Canada had made limited } \\
\text { investment in BIA capabilities and wished to understand a) } \\
\text { issues stemming from the lack of BIA capabilities in order to } \\
\text { build a business case for investment and b) input required to } \\
\text { develop a BIA strategy and roadmap. }\end{array}$ \\
\hline $\begin{array}{l}\text { Property Valuation } \\
\text { Services } \\
\text { Corporation (PVSC) }\end{array}$ & 150 & $\begin{array}{l}\text { This governmental agency, based in eastern Canada, sought to } \\
\text { understand the strengths and weaknesses of existing BIA } \\
\text { capabilities in order to develop a business case for future } \\
\text { investment and a long term BIA strategy. }\end{array}$ \\
\hline
\end{tabular}

Table 4. Participating organization profiles.

We approached a number of organizations with the goal of finding BIA "champions" - senior management personnel willing to advocate for a formal BIA assessment process within their organization. For organizations willing to undertake an assessment project, we struck oversight groups composed of both business and IT personnel. We attempted to staff the working groups with managers who a) oversaw the design and deployment of BIA capabilities or b) had oversight of business units with significant BIA needs. The oversight groups were critically important to the success of assessments - they defined and clarified the specific goals for the assessment, identified and recruited participants and worked, during the execution of each assessment, to ensure high participation rates within targeted groups. Many of the members of oversight groups subsequently played key roles in BIA business case and strategy development activities.

Once the specific goals for the organization were defined, we developed organization-specific versions of online surveys and invited a small group of pilot participants (technical staff, BIA users and senior business leaders) to complete the instrument designed for their role. At the first organization we engaged, the automobile manufacturer, the pilot group consisted of approximately 50 individuals. We found the feedback from the pilot participants to be extremely useful as it allowed us to address issues related to understandability, relevance and survey completion time requirements. Typically, the pilot exercise resulted in a moderate degree of rework to the instruments. Once the instruments were finalized, they were sent to all targeted participants. On completion of the assessment, we analyzed the results and packaged them for subsequent use in strategy development activities.

\section{Feedback from Participating Organizations}

At the conclusion of each assessment project, we engaged BIA champions, namely the CIO of the municipal government, the CEO of the PVSC, and the BIA strategy development project manager of the automaker in semi-structured interviews in order to gain an understanding of the relevance and utility of our BIAED framework and diagnostic instruments. Overall, the feedback received was instructive and clearly indicated the usefulness of our artefacts. The project champions were unanimous in the view that the framework proved useful for examining the current state of BIA capabilities and the diagnostic toolkit delivered quantitative and qualitative results essential for building investment business cases and for developing BIA strategies. As stated by the CEO of PVSC

"As part of theimplementation of BIA in PVSC, we conducted a diagnostic survey with staff to examine the current state of information management and its challenges. This 
tool proved to be extremely valuable in building the necessary business case we required to formally proceed with a BIA initiative. I would highly recommend this as a key step in any organization's BIA journey."

This view was supported by the CIO of Halifax Regional Municipality who asserted that

"The diagnostic instrument provided the foundation for HRM's BIA strategy and business case. It effectively identified and quantified the impacts of issues in our current environment related to manual data integration, data quality and other key areas. It provided actionable information that allowed us to identify and prioritize our actions moving forward."

The champions pointed out that the online diagnostic toolkit was useful for gaining a multiplestakeholder perspective on BIA capabilities in the organization. Further, the compilation and synthesis of qualitative data (i.e. respondent commentary) was found to be very useful and directional. In fact, the BIA strategy development manager for the large auto manufacturer commented that,

"Initially, many in the IT group were sceptical of the value of using surveys to support BIA strategy. However, on completion of the project, there was universal agreement that the surveys provided tremendous value. The findings were surprising and fundamentally altered our perception of what the focus of our future BIA strategy should be. The level of insight provided by the BIA assessment toolkit could not have been obtained any other way."

Also, the champions remarked that the framework was useful because it considered the technical team's perspective on what they think end-user perceptions are. They believed that comparing what the technical team views user perceptions to be to actual perceptions often yielded interesting insights and could be employed to improve business-IT alignment.

\section{Concluding Remarks}

As organizations continue to make ever-larger investments in BIA capabilities to support an expandingarray of organizational decision making activities, effective and efficient approaches for BIA capability assessment becomes an essential tool. Leveraging a design science approach, this paper presents a practical and useful framework and toolkit for this specific purpose.

Per Hevner's first design science guideline, we developed two artefacts - a comprehensive BIA effectiveness diagnostic (BIAED) framework (i.e., a model) and an online diagnostic toolkit (i.e., an instantiation). The framework encompasses three main perspectives: the coverage of effectiveness dimensions; the process context for assessment; and the constituencies from whom input must be sought. This research addresses the problem of efficiently diagnosing the effectiveness of current state BIA capabilities across critical dimensions from the perspective of multiple stakeholder groups which is a critical (unaddressed) problem for many organizations today, thus conforming to Hevner's second guideline - problem relevance. We designed novel artefacts that have been informed by, and incorporate elements of, previously developed maturity models practically test their efficacy through large-scale deployment and evaluation in three organizations (Hevner et al.'s Guideline 5 - research rigor).

The utility of the artefacts was evaluated in two ways - by piloting the deployment of survey instruments within each organization and through interviews with BIA champions at the conclusion of each engagement (Hevner et al.'s Guideline 3 - design evaluation and Guideline 5 - research rigor). Participant feedback was and will continue to be used to refine the designed artefacts for future deployments. As such, this iterative "build-and-evaluate" loop conforms to Hevner et al.'s Guideline 6 - design as a search process.

In this paper we present the framework and representative sample of the survey questions associated with the online toolkit. We have presented the framework and toolkit within each of the organizations that we have collaborated with and have received feedback from both technical and managerial personnel that the artefacts are comprehensible and relevant. We 
therefore believe that the results of our research are presented in such a way as to be informative to both technical and management audiences, thus conforming to Hevner et al.'s Guideline 7 - communication of research. The two artefacts presented in this paper represent our research contribution (guideline 4 - research contributions). The BIAED framework and associated diagnostic toolkit provide organizations with a practical, effective means to evaluate current BIA capabilities and to incorporate evaluation results into strategy development processes. We thus provide a fully formed operational model and practical tools for BIA effectiveness / maturity assessment, which have not been addressed by prior studies.

As for future research, we plan to continue to refine the BIAED framework and the associated toolkit by deploying them within a variety of organizational contexts. A key goal for our future research is to deploy and evaluate the artefacts in geographies outside of North America to determine if the framework requires modification in order to be effective in different geographies and cultures.

\section{References}

Arnott, D., \& Pervan, G. (2012). Design science in decision support systems research: An assessment using the Hevner, March, Park, and Ram Guidelines. Journal of the Association for Information Systems, 13(11), 923-949.

Barrett, D., \& Barton, N. (2006) Best practices in building a data warehouse quickly, Business Intelligence J ournal, 11(4), 37-45.

Brooks, P., El-Gayar, O. \& Sarnikar, S. (2015) A framework for developing a domain specific business intelligence maturity model: Application to healthcare, International J ournal of Information Management, 35, 337-345.

Bucher, T., Gericke, A., \& Sigg, S. (2009) Process-centric business intelligence, Business Process Management J ournal, 15(3), 408-429.

Cates, J . E., Gill, S. S. \& Zeituny, N. (2005) The Ladder of Business Intelligence (LOBI): a framework for enterprise IT planning and architecture, International J ournal of Business Information Systems, 1(1), 220-238.

Chrissis, M. B., Konrad, M. \& Shrum S. (2011) CMMI for Development: Guidelines for Process Integration and Product Improvement, Addison-Wesley Professional.

Chuah, M-H. \&Wong, K-L. (2011) A review of business intelligence and its maturity models." African J ournal of Business Management, 5(9), 3424- 3428.

Chen, H., Chiang, R. H., \& Storey, V. C. (2012). Business Intelligence and Analytics: From Big Data to Big Impact. MIS Quarterly, 36(4), 1165-1188.

Chuah, M-H. \& Wong, K-L. (2012) Construct an Enterprise Business Intelligence Maturity Model (EBI2M) Using an Integration Approach: A Conceptual Framework. In: Mircea, M. (eds.), Business Intelligence - Solution for Business Development, InTech, 1-14.

Cosic, R., Shanks, G. \& Maynard, S. (2012) Towards a business analytics capability maturity model, Proceedings of the 23rd Australasian Conference on Information Systems, Geelong, Victoria, Australia, 1-11.

Couture, N. (2013) Best practices for adopting agile methodologies for data warehouse development, Business Intelligence J ournal, 18, 8-17.

Davenport, T. H. \&Harris J . G. (2007) Competing on Analytics: The New Science of Winning, Cambridge, MA: Harvard Business School Press.

Deng, R. (2007) Business Intelligence Maturity Hierarchy: ANew Perspective from Knowledge Management, Information Management, Available at: http://www.informationmanagement.com/infodirect/ 20070323/ 1079089-1.html 
Eckerson, W. (2007) TDWI Benchmark Guide: Interpreting Benchmark Scores Using TDWI's Maturity Model, TDWI Research. Available at: http://tdwiorg0000.web711.discountasp.net/Content/TDWI_Benchmark_Final.pdf

Eckerson, W. (2009) TDWI's Business Intelligence Maturity Model, The Data Warehousing Institute, Chatsworth.

Fedouaki, F., Okar, C. \&El Alami, S. (2013) A maturity model for Business Intelligence System project in Small and Medium-sized Enterprise: An Empirical investigation, International J ournal of Computer Science Issues, 10(6), 61-69.

Fisher, T. (2005) How mature is your data management environment? Business Intelligence J ournal, 10(3), 20-26.

Foshay, N., Taylor, W., \& Mukherjee, A. (2014) Winning the Hearts and Minds of Business Intelligence Users: The Role of Metadata, Information Systems Management, 31(2), 167-180.

Gartner Press Release (2014) Gartner Says Worldwide Business Intelligence and Analytics Software Market Grew 8 Percent in 2013, Stamford, Conn., April, 29, 2014, Press Release. Available at: http:/ / www.gartner.com/newsroom/id/ 2637615

Gudfinnsson, K., Strand, M. \&Berndtsson, M. (2015) Analyzing business intelligencematurity, J ournal of Decision Systems, 24(1), 37-54.

Hagerty, J. (2006) AMR Research's Business Intelligence/ Performance Management Maturity Model, Version 2, Available at: http:// www.eurim.org.uk/ activities/ig/voi/AMR_Researchs_Business_Intelligence.pd $\mathrm{f}$

Hausladen, I. \& Hass, A. (2014) A J oint Maturity Model of BI-Driven Supply Chains, Proceedings of $14^{\text {th }}$ International Scientific Conference on Business Logistics in Modern Management, Osijek, Croatia, 97-108.

Hawking, P., Jovanovic, R. \& Sellitto, C. (2010) Business Intelligence Maturity in Australia, Victoria University ERP Research Group.

Hawking, P. (2011) Business Intelligence Excellence: A Company's J ourney to Business Intelligence Maturity, Proceedings of the 17th Americas Conference on Information Systems, Detroit, Michigan, USA, 1-9.

Hawking, P., \& Sellitto, C. (2015) Business Intelligence Strategy: A Utilities Company Case Study, International J ournal of Enterprise Information Systems, 11(1), 1-12.

Hevner, A. R., March, S. T., Park, J . \& Ram, S. (2004) Design Science in Information Systems Research, MIS Quarterly, 28(1), 75-105.

Hewlett Packard (2009) The HP Business Intelligence Maturity Model: Describing the BI journey, $\quad$ Available http:// www.computerwoche.de/ fileserver/ idgwpcw/ files/ 1935.pdf

Huang, T. C., Liu, C., \&Chang, D. (2012) An empirical investigation of factors influencing the adoption of data mining tools, International Journal of Information Management, 32(3), 257-270.

Isik, O., J ones, M. C., \& Sidorova, A. (2011) Business intelligence (bi) success and the role of BI capabilities, Intelligent Systems in Accounting, Finance and Management, 18(4), 161-176.

Kettinger, W. J . \& Marchand, D. A. (2011) Information Management Practices (IMP) from the Senior Manager's Perspective: An Investigation of the IMP Construct and Its Measurement, Information Systems J ournal, 21(5), 385-406. 
Lahrmann, G., Marx, F., Winter, R. \& Wortmann, F. (2011) Business Intelligence Maturity: Development and Evaluation of a Theoretical Model, Proceedings of the 44th Hawaii International Conference on System Sciences, Poipu, Kauai, Hawaii, 1- 10.

Marchand, D. A., Kettinger, W. J . \& Rollins, J. D. (2000) Information Orientation: People, Technology and the Bottom Line, Sloan Management Review, 41(4), 69-80.

Microsoft (2007) Business Productivity Infrastructure Optimization Campaign.

Miller, L., Schiller, D. \& Rhone, M. (2009) Data Warehouse Maturity Assessment Service, TERADATA, 1-15. Available at: http:/ / www.teradata.com/ assets/ 0/ 206/ 276/3457d45f7327-4a36-b1dc-2e5daae3d269.pdf

Olszak, C. \&Ziemba, E. (2007) Approach to Building and Implementing Business Intelligence Systems, Interdisciplinary J ournal of Information, Knowledge, and Management, 2(1), 135-148.

Popovic, A., Hackney, R., Coelho, P. S., \& J aklic, J . (2012) Towards business intelligence systems success: Effects of maturity and culture on analytical decision making, Decision Support Systems, 54(1), 729-739.

Raber, D., Winter, R. \& Wortmann, F. (2012) Using Quantitative Analyses to Construct a Capability Maturity Model for Business Intelligence, Proceedings of the 45th Hawaii International Conference on System Sciences, Grand Wailea, Maui, Hawaii, 4219-4228.

Rajteric, I. H. (2010) Overview of Business Intelligence Maturity Models, Management International J ournal of Contemporary Management Issues, 15(1), 47-67.

Rayner, N., Schlegel, K. (2008) Maturity Model Overview for Business Intelligence and Performance Management, Gartner, Stamford. Available at: https:/ / www.gartner.com/ doc/ 842813/ maturity-model-overview-business-intelligence

Rivera, D. S. \& Shanks, G. (2015) A Dashboard to Support Management of Business Analytics Capabilities, J ournal of Decision Systems, 24(1), 73-86.

Russell, S., Haddad, M., Bruni, M. \& Granger, M. (2010) Organic Evolution and the Capability Maturity of Business Intelligence, Proceedings of $16^{\text {th }}$ Americas Conference on Information Systems, Lima, Peru, 1-9.

Sacu, C. \& Spruit, M. (2010) BIDM: The Business Intelligence Development Model, Proceedings of the $12^{\text {th }}$ International Conference on Enterprise Information Systems, Funchal, Madeira, Portugal, 288-293.

SAS (2009) Information Evaluation Model, Available at: http:/ / www.sas.com/ software/ iem/

Schläfke, M., Silvi, R., \&Möller, K. (2012) A framework for business analytics in performance management, International J ournal of Productivity and Performance Management, 62(1), 110-122.

Sen, A., Sinha, A. \& Ramamurthy, K. (2006) Data Warehousing Process Maturity: An Exploratory Study of Factors Influencing User Perceptions, IEEE Transactions on Engineering Management, 53(3), 440-455.

Sen, A., Ramamurthy, K., \&Sinha, A. P. (2012) A model of data warehousing process maturity, IEEE Transactions on Software Engineering, 38(2), 336-353.

Sharma, R. S., \& Djiaw, V. (2011) Realising the strategic impact of business intelligence tools. VINE, 41(2), 113-131.

Shankaranarayanan, G., Even, A. D. I. R., \&Watts, S. (2006) The role of process metadata and data quality perceptions in decision making: an empirical framework and investigation. J ournal of Information Technology Management, 17(1), 50-67.

SMC (2009), Steria Mummert Consulting AG, Available at: http:// www.nomina.de/ cognos/pdf/ 1s017_co.pdf 
Stock, P. (2013) The Business Intelligence Maturity Model: describing the BI journey, Available at: http:// www.young-blood.co.za/index.php/2013-02-10-10-55-36/ miningand-operations/item/20-bi-maturitymodel

Tan, C. S., Sim, Y. W., \& Yeoh, W. (2011). A maturity model of enterprise business intelligence. Communications of the IBIMA, 2011(417812), 1-11.

Thamir, A., \& Theodoulidis, B. (2013). Business Intelligence Maturity Models: Information Management Perspective. In: Skersys, T., Butleris, R. and Butkiene, R. (eds), International Conference on Information and Software Technologies (ICIST), Communications in Computer and Information Sciences (CCIS), 403, Springer, 198221.

Verkooij, K., \& Spruit, M. (2013) Mobile Business Intelligence: Key Considerations For Implementations Projects, J ournal of Computer Information Systems, 54(1), 23-33.

Wang, R. Y., \& Strong, D. M. (1996) Beyond accuracy: What data quality means to data consumers, J ournal of management information systems, 12(4), 5-33.

Watson, H. J., \& Haley, B. J. (1998) Managerial considerations, Communications of the ACM, 41(9), 32-37.

Watson, H., Ariyachandra, T. \&Matyska, J r, R. J . (2001) Data Warehousing Stages of Growth, Information Systems Management, 18(3), 42-50.

Watson, H. (2013) All About Analytics, International Journal of Business Intelligence Research, 4(1), 1-16.

Wixom, B. \&Watson H. (2010) The BI-Based Organization, International J ournal of Business Intelligence Research, 1(1), 13-28.

Williams, S. \& Williams, N. (2007) The Profit Impact of Business Intelligence, Morgan Kaufmann Publishers, San Francisco.

Yeoh, W., \& Popovic, A. (2015). Extending the understanding of critical success factors for implementing business intelligence systems. J ournal of the Association for Information Science and Technology. DOI: 10.1002/ asi.23366

Copyright: (c) 2015 Foshay, Yeoh, Boo, Ong \& Mattie. This is an open-access article distributed under the terms of the Creative Commons Attribution-NonCommercial 3.0 Australia License, which permits non-commercial use, distribution, and reproduction in any medium, provided the original author and AJ IS are credited.

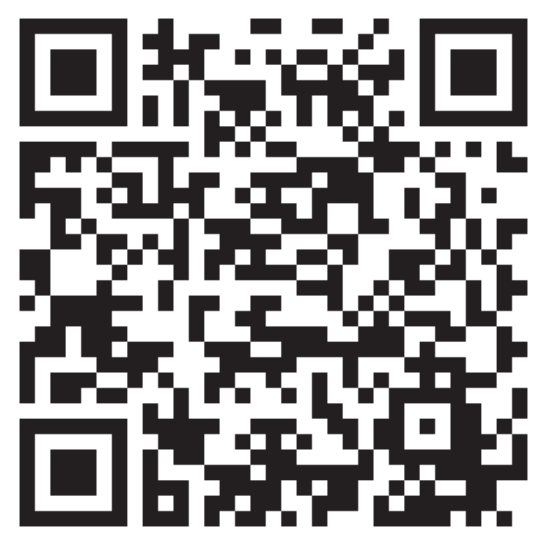

